\title{
IDENTIFIKASI SENI BUDAYA BERNUANSA KEAGAMAAN DI PALU DAN POSO SULAWESI TENGAH
}

\section{THE INDENTIFICATION OF RELIGIOUS CULTURE AND ART IN PALU AND POSO REGENCIES, CENTRAL SULAWESI}

\author{
Nurman Kholis \\ Puslitbang Lektur, Khazanah Keagamaan, dan Manajemen Organisasi \\ Badan Litbang dan Diklat Kementerian Agama RI \\ e-mail: nukhdata@yahoo.com/nurmankholis@gmail.com
}

Naskah diterima tanggal 5 Oktober 2017. Naskah direvisi 17 Oktober 2017. Naskah disetujui 30 Oktober 2017.

\begin{abstract}
Abstrak
Penelitian ini bertujuan untuk mengidentiksasi seni dan budaya bernuansa keagamaan yang masih eksis di kota Palu dan Kabupaten Poso Sulawesi Tengah meliputi sistem agama dan politik, adat istiadat, bahasa, perkakas, pakaian, bangunan, dan karya seni. Penelitian ini bersifat deskriptif-kualitatif. Adapun langkah-langkahnya dilakukan melalui eksplorasi, inventarisasi, dan kajian atas nuansa keagamaan dalam seni dan budaya tersebut. Adapun sebaran berdasarkan nuansa agama pada nama-nama seni dan budaya keagamaan tersebut terdiri dari: 4 buah bernuansa animisme/dinamisme yaitu: Patung Tadulako, Patung Langke Bulava, Kalamba, dan Patung Palindo; 12 buah bernuansa Islam yaitu: musik Kakula, Upacara Nopamada, Musik Gambusu, Rabana, Suaka Nuwiata, mantra untuk percintaan, mantra untuk menundukan orang sombong, mantra untuk bertani, tradisi selamatkan jabang bayi, upacara tolak bala sebelum melaut, Nogero Jene (Membatalkan Air Wudu), dan Tari Jeppeng; 3 buah bernuansa Kristen yaitu: Padungku (Upacara Paska Panen), Upacara perkawinan Adat Pamona, dan Adat Pesta Rambu Solo, 2 buah bernuansa Hindu yaitu: Upacara Potong Gigi dan Krama Adat Kerta Winangun.
\end{abstract}

Kata kunci: seni budaya, bernuansa keagamaan, musik kakula, musik gambusu.

\begin{abstract}
This study aims to identify religious art and culture that still exist in the city of Palu and Kabupaten Poso, Central Sulawesi, covering religious and political systems, customs, language, tools, clothing, buildings and artwork. This research is descriptive-qualitative. The research steps were conducted through exploration, inventory, and studies on religious nuances in the arts and culture. The distribution based on religious nuance in the names of art and religious culture consists of: 4 pieces of animism/dynamism nuances are: Tadulako Statue, Langke Bulava Statue, Kalamba, and Statue of Palindo; 12 nuances of Islam: Kakula music, Nopamada ceremony, Gambusu music, Rabana, Nuwiata sanctuary, mantra for romance, mantras for bowling, boasting, Wudu), and Jeppeng Dance; 3 pieces of Christian nuances are: Padungku (Post Harvest Ceremony), Ceremony of Adat Pamona, and Adat Pesta Rambu Solo, 2 pieces of Hindu nuance namely: Cutting Ceremony and Krama Indigenous Kerta Winangun.
\end{abstract}

Keywords: art culture, religious nuance, kakula music, gambusu music.

\section{PENDAHULUAN}

Kebudayaan adalah keseluruhan gagasan, perilaku, danhasilkaryamanusiayangdikembangkan melalui proses belajar dan adaptasi terhadap lingkungannya yang berfungsi sebagai pedoman untuk kehidupan bermasyarakat, berbangsa, dan bernegara (Renstra Ditjen Kebudayaan, 2010-2014: 6). Adapun budaya merupakan suatu cara hidup yang berkembang dan dimiliki bersama oleh sebuah kelompok orang dan diwariskan dari generasi ke generasi. Dengan demikian, budaya terbentuk dari unsur yang rumit, termasuk sistem sistem agama dan politik, adat istiadat, bahasa, perkakas, pakaian, bangunan, dan karya seni.

Menurut Direktorat Jenderal Kebudayaan Kementerian Pendidikan dan Kebudayaan, budaya keagamaan dapat pula dikatakan sebagai tradisi keagamaan. Hal ini sehubungan dengan agama-agama di penjuru bumi ini yang secara historis muncul dan berkembang seiring dengan 
pemahaman dan penghayatan manusia atas dunia dan lingkungannya. Dengan demikian, diasumsikan, agama berkembang selaras dengan perkembagan manusia berpikir. Pengalaman-pengalaman metafisis yang dialami dan kemudian diyakini oleh manusia maupun sekelompok manusia tertentu. Agama disebut sebagai salah satu unsur pembentuk sistem kebudayaan karena hampir selalu sebuah kelompok sosial atau kebudayaan memiliki corak religiusitas tertentu.

Salah satu provinsi di Indonesia yang memiliki keragaman seni dan budaya adalah Sulawesi Tengah. Selain penduduk asli, Sulawesi Tengah dihuni pula oleh transmigran seperti dari Bali, Jawa, Nusa Tenggara Barat dan Nusa Tenggara Timur dengan masyarakat Bugis dan Makassar serta etnis lainnya di Indonesia sejak awal abad ke-19 dan sudah membaur. Jumlah penduduk di daerah ini yang mayoritas beragama Islam, lainnya Kristen, Hindu dan Buddha. Musik dan tarian di Sulawesi Tengah bervariasi antara daerah yang satu dengan lainnya. Musik tradisional memiliki instrumen seperti suling, gong dan gendang. Alat musik ini lebih berfungsi sebagai hiburan dan bukan sebagai bagian ritual keagamaan. Di wilayah beretnis Kaili sekitar pantai barat - waino musik tradisional - ditampilkan ketika ada upacara kematian. Kesenian ini telah dikembangkan dalam bentuk yang lebih populer bagi para pemuda sebagai sarana mencari pasangan di suatu keramaian. Karena itu, nanyak tarian yang berasal dari kepercayaan keagamaan dan ditampilkan ketika festival. Pada masa sebelum masuknya agama Islam dan Kristen, upacara-upacara adat seperti ini masih dilakuan dengan manteramantera yang mengandung animisme (dalam http: //nadhy-math.blogspot. com/2012/01, diakses pada 17/7/2017).

Setelah masuknya kedua agama ini, pesta perkawinan dan kematian sudah disesuaikan antara upacara adat setempat dengan upacara menurut agama penganutnya. Karena itu, berbagai seni kebudayaan Sulawesi Tengah tentu menjadi bagian dari kebudayaan nasional Indonesia. Semua tradisi yang berkaitan dengan aspek kehidupan di wilayah ini banyak yang masih dipelihara dalam kehidupan masyarakat sehari-hari. Kepercayaan lama mungkin merupakan salah satu warisan budaya yang tetap terpelihara hingga sekarang dan dilakukan dalam beberapa bentuk dengan berbagai pengaruh modern serta pengaruh agama (dalam http: //mutia-dwi. blogspot.com/2012/03/budaya-sulawesi-tengah- dan-seni.html, diakses pada 3/6/2017).

Dalam perkembangan selanjutnya, teknologi modern telah memperlancar kontak-kontak berbagai budaya dan agama. Karena itu, kontestasi antara berbagai budaya dan agama pun tidak dapat dihindarkan. Dengan demikian, seni dan budaya bernuansa keagamaan yang telah dihasilkan oleh masyarakat Sulawesi Tengah diasumsikan sudah banyak yang punah, ada yang masih tetap bertahan namun terancam punah, ada yang tetap bertahan, dan ada yang mengalami pergeseran.

Penelitian ini bertujuan mengidentifikasi nama-nama seni dan budaya bernuansa keagamaan yang dapat ditemukan di Kota Palu dan Kabupaten Poso Sulawesi Tengah, dan mendeskripsikan nuansa keagamaan dalam seni dan budaya tersebut.

\section{Tinjauan Pustaka}

Kegiatan bersifat eksploratif terhadap seni dan budaya di Sulawesi Tengah telah dilakukan oleh Muhammad As'ad, peneliti Balai Litbang Agama Makassar pada 2014. Kegiatan ini bernama Inventarisasi Seni dan Budaya Nusantara di Provinsi Sulawesi Tengah Tahun 2014 dalam Laporan Penelitian Inventarisasi Seni dan Budaya Nusantara, Balai Litbang Agama Makassar Bidang Lektur dan Khazanah Keagamaan Tahun Anggaran 2014. Hasil inventarisasi yang telah dilakukan berdasarkan beberapa kategori tertentu, sebagai berikut: Instrumen musik: Kakula, Nggeso-ngeso, gambagamba, gimba, ganda, lalove; Tari tradisional: Tari Dero, Tari Raego, Balia; Penjemputan: Pontanu, No Talua, Marobe, Mopuputi, dan Menambu; Seni suara: Lagi Kaili Ntovea, "Kaluku", dan Qasidah; Upacara mohavu (penyebaran benih), paruja (pengolahan sawah), mompanga (saat padi menguning), mo vunja (persembahan kepada pemberi hasil panen); Vunja To Manuru (pengobatan atau penyembuhan penyakit); Vunja Tarade (acara gembira); Vunja Poraa Binangga (meminta hujan kepada penguasa langit); Vunja Mpae (simbol syukur karena berhasilnya panen); Movunja mencakup: Membangu vunja, Popele Bayasa, Endaloe, dan Rego (dalam http: //mutiadwi.blogspot.com/2012/03/budaya-sulawesitengah-dan-seni.html, diakses pada 3/6/2017).

\section{METODE PENELITIAN \\ Jenis Penelitian}

Penelitian ini bersifat deskriptif-kualitatif. Adapun langkah-langkahnya dilakukan melalui eksplorasi, inventarisasi, dan kajian atas nuansa keagamaan dalam seni dan budaya tersebut. Teknik 
untuk identifikasi seni dan budaya keagamaan ini dilakukan dengan cara: Studi pustaka terkait sejarah, budaya, dan agama di Sulawesi Tengah dari berbagai buku, majalah, dan internet; Observasi, pada lembaga terkait budaya dan agama antara lain Kementerian Agama Provinsi Sulawesi Tengah, Dinas Pariwisata dan Budaya Provinsi Sulawesi Tengah, Dewan Kesenian Sulawesi Tengah, perpustakaan perguruan tinggi di kota Palu (Universitas Tadulako, IAIN Datokarama), museum, tokoh masyarakat, dan penggiat seni dan tradisi keagamaan; Wawancara, dengan pejabat Kementerian Agama dan Dinas Pariwisata dan Budaya Provinsi Sumatera Selatan, dan Dewan Kesenian Sulawesi Tengah di kota Palu; Menginventarisasi, nama-nama seni dan budaya keagamaan berikut mengungkapkan konteks keagamaan dalam seni dan budaya tersebut.

\section{PEMBAHASAN}

\section{Sekilas Sejarah dan Perkembangan Seni dan Budaya Keagamaan \\ Periode Animisme/Dinamisme}

Berkenaan dengan perkembangan budaya dan agama di Sulawesi Tengah, menurut Arkeolog pada Museum Negeri Sulawesi Tengah, Iksam, kebudayaan Austronesia sebelum menyebar ke kawasan Asia Pasifik-Selandia baru hingga Madagaskar justru diperkirakan berasal dari tanah Lore yang kini termasuk wilayah Kabupaten Poso Sulawesi Tengah. Hal ini sebagaimana adanya buktibukti tinggalan Megalitik yang memiliki kekhasan di dunia. Karena itu, menurutnya anggapan yang selama ini menyebutkan bahwa nenek moyang bangsa Indonesia berasal dari daratan Cina Selatan perlu ditinjau kembali sehubungan dengan adanya bukti megalitik tersebut. Sebab, menurut sarjana Arkeologi Universitas Hasanuddin dan Magister Museologi Universitas Padjadjaran ini, penyebaran manusia dari dataran tinggi Lore-lah yang kemudian menyebar ke berbagai kawasan di Asia dan Pasifik (Abubakar, 2012: 65-66).

Iksam, yang pernah mengikuti studi Museum di Perancis dan dilibatkan dalam penelitian Shujitsu University Japan dan STORMA Jerman, menjelaskan, Kalamba itu hanya ada di Sulawesi Tengah yang merupakan bejana batu. Kemiripan Kalamba di Lore hanya di lembah sungai Mekong dataran CinaSelatan yang sekarang termasukwilayah Laos. Karena itu, ia pun menjelaskan tulisan dalam buku-buku sejarah di sekolah bahwa nenek moyang Indonesia berasal dari Cina Selatan sebenarnya berdasarkan kemiripan bentuk tinggalan megalitik.
Menurutnya, sebutan Kalamba berasal dari Lore Kuno yang artinya perahu. Fungsinya adalah untuk penguburan yang dipercaya sebagai perahu arwah untuk menuju ke suatu alam (Abubakar, 2012: 70).

Berdasarkan bukti-bukti yang diperoleh, maka diketahui tinggalan megalitik di Pasifik itu asalnya dari dataran tinggi Lore yang membawa kebudayaan tersebut ke sana. Pendapat Iksam ini sejalan dengan pendapat begawan arkeologi Indonesia RP Soejono (1926-2010) saat melakukan penelitian di tanah Lore tahun 1999 yang ia temani. RP Soejono sebelum ke Lore ia telah berkeliling dunia untuk mempelajari tinggalan purbakala megalitik. Ia pun menyatakan, dengan melihat tinggalan di Lore, maka teori tentang orang-orang dari Cina Selatan yang datang ke Indonesia perlu dikaji kembali. Sebab, seharusnya orang dari Tanah Lore Sulawesi Tengah yang ke Cina. Hal ini sehubungan dengan ketuaan tinggalan megalit di Lore dibanding di Cina Selatan (Abubakar, 2012: $71)$.

Berdasarkan peninggalan yang ditemukan di Sulawesi Tengah diketahui bahwa manusiamanusia prasejarah di wilayah ini telah mengenal seni pembuatan patung (arca), seni lukis dan seni pembuatan alat-alat perunggu dan alat-alat tanah liat, seni tari dikaitkan dengan acara ritual pemujaan arwah dan animism. Hal ini sebagaimana dapat dilihat pada hiasan-hiasan yang dijumpai di Lore Utara. Di sana terdapat lukisan kepala orang, buaya dan lain-lain yang menunjukkan bahwa mereka percaya pada adanya kekuatan-kekuatan gaib atau pada benda-benda dan makhluk hidup, kekuatan itu terdapat di bagian-bagian tubuh tertentu seperti di kepala manusia. Demikian pula patung-patung nenek moyang yang sengaja dibangun untuk kepercayaan pemujaan. Dengan kepercayaan terhadap adanya mana atau kesaktian pada semua benda dan tempat-tempat tertentu, maka menggunakan mana tadi muncullah magi (Sutrisno dkk., 2005: 26).

Penjelasan Iksam juga diperkuat dengan hasil penelitian Tim peneliti dari University of Wollongong di Australia menyatakan bahwa lukisan gua di Sulawesi adalah yang tertua di dunia. Dua dari tim peneliti tersebut, yaitu Anthony Dosseto, yang merupakan peneliti senior di School of Earth and Environmental Sciences di University of Wollongong, Australia, dan Thomas Sutikna, arkeolog Indonesia, yang sedang melakukan penelitian di universitas yang sama. Menurut keduanya, lukisan-lukisan kuno antara lain 
ditemukan di tujuh gua di Sulawesi Tengah dan Di gua Leang Pettakere Sulawesi Selatan. Lukisanlukisan tersebut berupa stensil tangan Sulawesi yang diperkirakan paling sedikit berumur 40 ribu tahun (Sutrisno dkk., 2005: 27).

Lukisan tersebut adalah yang paling tua yang pernah ditemukan di luar Eropa. Dengan demikian, setelah ditemukan lukisan tertua tentang binatang di dalam gua-gua di Sulawesi menunjukkan bahwa 40 ribu tahun lalu, manusia purba Indonesia juga menunjukkan kemampuan artistik yang sama. Lukisan-lukisan gua ini pertama kali dilaporkan oleh arkeolog Belanda Heeren-Palm tahun 1950-an. Ia menuliskan lukisan-lukisan di gua Leang Pattae di Maros, namun sejak itu tidak ada yang mencoba menentukan umurnya. Hal ini terjadi karena para arkeolog percaya bahwa itu adalah bagian dari er pra-Neolitik, sekitar 10 ribu tahun lalu (dalam http: //www.dw.com/id/interview-sejarah-seni-purbaperlu-ditulis-ulang/dan http: //www.dw.com/id/ lukisan-gua-sulawesi-menulis-kembali-sejarah/, diakses pada 24/5/2017).

Sementara itu, di salah satu kabupaten di Sulawesi Tengah yaitu Poso juga terdapat kesenian berupa nyanyian Motengke untuk orang mati, Mojonjoava untuk menjaga orang mati. Isinya merupakan riwayat perjalanan hidup seorang mulai hidup di dunia hingga di dunia arwah. Keyakinan yang dipeluk oleh masyarakat zaman kuno di Sulawesi Tengah itu merupakan kelanjutan dari zaman prasejarah. Adapun latar belakang kepercayaan mereka didasarkan pada totalitas alam sebagai makrokosmos. Dewa-dewa yang dipuja sudah lebih dipersonifikasikan pada penguasa yang langsung mempengaruhi sumber kehidupannya seperti dewa penguasa tanah dan dewi pelindung tanaman (Sutrisno dkk., 2005: 27).

Kepercayaan animism dan dinamisme ini dilakukan dengan pemujaan terhadap zat gaib yang disebut pilogot. Adapun tata cara mendatangkan pilogot dibacakan oleh tarapuh dengan membaca mantra-mantra lebih dahulu untuk memanggil pilogot itu turun ke bumi. Pilogot inilah yang mereka anggap dapat memberikan pengaruh, baik kepada mereka kalau diadakan upacara-upacara untuknya dan akan membawa bencana apabila pilogot ini marah. Paham dinamisme dapat dijumpai dalam kepercayaan mereka. Hal ini dapat membawa pengaruh pada kesehatan/ keselamatan mereka, misalnya sepotong gelang tembaga kalau diredam, maka air peredam tadi dapat menyembuhkan orang sakit. Setelah kedatangan pengaruh kekuasaan
Ternate yang pada waktu itu sudah memeluk Islam, maka ajaran Islam pun sampai di Kerajaan Banggai. Namun, dalam kehidupan sehari-hari terjadilah percampuran antara ajaran Islam dengan adat kebiasaan lama yang sudah melembaga dalam tata cara kehidupan masyarakat. Tradisi megalit tidak dikenal oleh generasi masa kini di Lore sehubungan terjadi generasi yang terputus dari masyarakat pendukung budaya megalit di Lore. Namun, setidaknya jika dilihat dari studi etnologi masih ada unsur-unsur budaya lama yang melekat pada masyarakat Lore. Sebab, dilihat dari simbolsimbol wajah patung yang ada secara fisik anatomi tubuhnya memiliki ciri yang sama. Hal ini seperti atribut-atribut yang mereka pakai seperti patung yang memakai ikat kepala yang disebut pakebalu yang sampai kini masih dipakai orang-orang Lore. Selain itu, juga ada tonjolan di kepala yang merupakan pakaian siga (ikat kepala) terbuat dari kulit kayu (Sutrisno dkk., 2005: 75).

Berkenaan patung manusia umumnya berada di dataran tinggi dan lumpang batu dan peralatan rumah tangga di dataran rendah, Iksam menuturkan bahwa hal itu bisa dilihat dari pandangan secara geografis dan pandangan dari konsep budaya. Dari konsep budaya masa megalitik ini yang diawal neolitik di situlah berbagai profesi dalam masyarakat sehingga menimbulkan suatu kekuatan religi yang sangat besar dan pemahaman neolitik sangat berkembang pesat dalam memuja leluhur.. Masyarakat megalitik ini diberikan dasar pemahaman kepercayaan bahwa semakin tinggi suatu tempat semakin dekat dengan dunia arwah atau dunia leluhur. Karena itu, pemahaman lokasi seperti ini karena pada masa itu orang hidup nomaden. Dengan demikian, patung megalit tersebut memiliki fungsi sakral, ada yang semi sakral dan ada yang profan untuk kebutuhan sehari-hari. Adapun arca menhir tergolong tinggalan sakral sehingga harus berada di dataran yang tinggi. Perbandingan ini sebagaimana pada piramid di Amerika Selatan yang berada di tempat yang tinggi. Demikian pula candi Sukuh di Jawa Timur yang motifnya perpaduan Hindu awal dan zaman megalitik itu berada di tempat tinggi karena dianggap ideal untuk berkomunikasi dengan dunia dewa (Sutrisno dkk., 2005: 72-73).

\section{Periode Sejak Masuknya Islam}

Pada zaman kuno, agama sama dengan kesenian. Hal ini sebagaimana seni tari, musik, dan nyanyi yang umumnya dikaitkan dengan upacara 
penyembahan roh, di samping untuk pergaulan muda-mudi di saat tertentu menurut adat. Dengan masuknya ajaran Islam, seni baca al-Quran dan zikir selalu diadakan pada saat-saat tertentu seperti pada bulan Ramadhan. Pada waktu kematian, keselamatan, perkawinan, dan sebagainya. Khusus untuk Lembah Palu dengan datangnya mubalig Dato Karama, mulai pula dikenal alat musik kakula, gamba-gamba, gambus, gong serta tanda kebesaran upacara ula-ula (Sutrisno dkk., 2005: 86).

Pada masa itu, pedalaman Sulawesi masih tetap pada kepercayaan animisme yang dikenal sejak zaman kuno, kecuali daerah pesisir yang mulai mendapat pengaruh ajaran Islam, karena persebaran ajaran ini mengikuti rute perdagangan. Adapun kerajaan yang mula-mula menerima ajaran Islam di Sulawesi Tengah adalah Kerajaan Buol dan Kerajaan Banggai kira-kira pertengahan abad XVI. Kedua kerajaan ini merupakan daerah pengaruh Kesultanan Ternate yang telah menerima ajaran Islam sejak abad XV.

Ajaran Islam tiba di Tanah Kaili diduga nanti pada abad XVII seperti dalam buku "Mengenal Tanah Kaili". Pada abad XV agama Islam mulai masuk di tanah Kaili dibawa oleh Abdul Raqie gelar Datuk Karama. Karena itu, disimpulkan bahwa pembawa agama Islam itu adalah dua orang mubalig yang berasal dari Minangkabau dengan nama popular yaitu Datuk Karama dan Datuk Mangaji (Sutrisno dkk., 2005: 88).

Menurut Buya Hamka dalam buku Kebudayaan dan Perjuangan Kemerdekaan Indonesia di Aceh, mubaligh bertiga dari Minangkabau ke Makassar yaitu Datuk Ritiro, Datuk Ribandang, dan Datuk Patimang berangkat dari Minangkabau adalah atas persetujuan dari Aceh. Adapun berkenaan kedatangan Datuk Karama ke Lembah Kaili berdasarkan tradisi lisan adalah bersama rombongan keluarga dengan para pengikutnya sebanyak \pm 50 orang. Mereka terdampar di Teluk Palu dan membawa peralatan antara lain: alat adat kebesaran berupa bendera kuning, panji orang-orang (Ula-Ula), Puade, Jijiri, Bulo dan alat bunyi-bunyian seperti: gong (tawaktawak), kakula (kulintang), gimba dan gambagamba (Sutrisno dkk., 2005: 89).

Secara umum kedatangan ajaran Islam ke Sulawesi Tengah melalui tahapan berikut ini: a. dari Ternate, b. Dari Minangkabau kemudian dilanjutkan oleh orang-orang Bugis, Mandar, c. Terakhir dilanjutkan pula oleh orang Arab (Sutrisno dkk., 2005: 90). Pada abad XIX seni budaya berasal dari barat belum ada, meskipun secara politis sudah ada pengaruh dari Belanda. Karena itu, pengaruh kebudayaan Islam seperti dalam seni bangunan tempat ibadah atau masjid, tatakrama pergaulan, kesenian, dan sebagainya. Pengaruh Bugis-Makassar ikut memperkaya perkembangan kebudayaan di Sulawesi Tengah. Hal ini seperti dalam tata pemerintahan, bangunan rumah, adat kebiasaan masyakarakat dalam berpakaian, masakan, dan sebagainya (Sutrisno dkk., 2005: 117).

Ajaran Islam makin luas dan bertambah penganutnya, tetapi kepercayaan lama masih berpengaruh di sebagian penduduk. Karena itu, dalam kehidupan sehari-hari terjadi pencampuran antara kepercayaan Islam dengan kepercayaan lama. Hal ini seperti dalam upacara tertentu seperti kematian, kelahiran, dan perkawinan kelihatannya adat lama masih tetap besar pengaruhnya. Demikian halnya pada pada kebiasaan menziarahi kuburan keramat, tempat angker dalam hubungan nazar kalau suatu keinginan tercapai merupakan kebiasaan lama yang masih hidup dalam masyarakat (Sutrisno dkk., 2005: 118).

Perkembangan seni budaya di Sulawesi Tengah pada abad XX antara lain dengan tersebarnya rebana ke Buol oleh orang-orang Banjar yang sekaligus mengajarkan lagu dan pukulan rebana. Sementara itu, orang Gorontalo mengajarkan lagu yang diambil dari kitab agama namanya Buruda. Orang Buol meniru mempraktekkan serta menambah jenis pukulan. Selanjutnya, orang Arab membawa gambus dan mengajarkan jepeng sehingga rebana dan gambus sangat berpenagruh di Buol. Mereka pun pada umumnya menjadi pandai melenged (berpantun, bersyair, berzikir, dan mengaji). Alat-alat musik pun tersebar di Buol seperti kalwah bawu, kecapi, tuwjanli, dan penuling (sejenenis suling). Orang-orang Buol juga memiliki kepandaian kerajinan tangan seperti mengukir pada perkakas. Selain itu, juga ada pejongge dari Bugis dan ronggeng dari Jawa yang dibawa oleh Raja Lahadun yang biasa dimainkan di pesta raja (Sutrisno dkk., 2005: 125).

\section{Periode Sejak Masuknya Kristen}

Agama Kristen mulai muncul pada akhir abad XVIII melalui kehadiran tokoh-tokoh zending seperti Kruijt dan Adriani kira-kira tahun 1895. Pada masa itu, Belanda baru dalam tahap survey atau penjajakan dan mulai aktif setelah mereka berhasil menguasai secara penuh Sulawesi Tengah pada awal abad XX. Karena itu, pengaruh seni 
budaya Eropa bernuansa Kristen pada abad XIX belum ada karena (1) terdapat garis pemisah antara lingkungan hidup orang Belanda dan masyarakat pribumi jelas, dan (2) masyarakat pribumi yang telah menganut agama Islam menganggap bahwa kebudayaan Eropa tidak sesuai dengan ajaran Islam (Sutrisno dkk., 2005: 118-129).

Pada 1892 berlabuh kapal "De Raaf” membawa Albertus Christian Kruijt yang bertugas sebagai utusan Zending untuk menyebarkan agama Kristen di Sulawesi Tengah. Kruijt selaku pendeta sekaligus antropolog dibantu oleh Adriani sebagai linguist. Keduanya bekerja keras untuk menyiarkan agama Kristen. Keduanya terlebih dahulu mempelajari adat kebiasaan dan bahasa kelompok suku yang terpencar dan bermusuh-musuhan dan selanjutnya berkeliling dari satu kelompok ke kelompok lainnya. Keduanya mempelajari dan mencatat hal-hal yang perlu diketahui agar usaha penginjilannya berhasil (Sutrisno dkk., 2005: 131-132).

Seiring masuknya penjajahan Belanda, lambat laun golongan terpelajar dan bangsawan menerima pengaruh cara kehidupan orang Belanda. Hal ini seperti cara berpakaian dan pemakaian bahasa Belanda terutama jika berhadapan dengan aparat Belanda. Agama Kristen yang dibawa oleh para utusan Zending berpengaruh terhadap pendidikan dan kesenian. Karena itu, pengaruh kebudayaan Islam dan Kristen dalam tata cara kehidupan sehari-hari, pendidikan dan kesenian sebagian besar bercorak Islam dan Kristen memperkaya kebudayaan daerah Sulawesi Tengah yang ada sebelumnya (Sutrisno dkk., 2005: 170).

Penduduk Sulawesi Tengah terdiri atas 19 kelompok etnis atau suku. Mereka adalah, etnis Kaili berdiam di Kabupaten Donggala dan Kota Palu, Kulawi berdiam di Kabupaten Donggala, Etnis Lore berdiam di Kabupaten Poso, Pamona berdiam di Kabupaten Poso, Mori berdiam di Kabupaten Morowali, Bungku berdiam di Kabupaten Morowali, Saluan atau Loinang berdiam di Kabupaten Banggai, Balantak berdiam di Kabupaten Banggai, Mamasa berdiam di Kabupaten Banggai, Taa berdiam di Kabupaten Banggai, Bare'e berdiam di Kabupaten Touna, Banggai berdiam di Banggai Kepulauan, Buol mendiami Kabupaten Buol, Tolitoli berdiam di Kabupaten Tolitoli, Tomini mendiami Kabupaten Parigi Moutong, Dampal berdiam di Dampal, Kabupaten Tolitoli, Dondo berdiam di Dondo, Kabupaten Tolitoli, Pendau berdiam di Kabupaten Tolitoli, dan Dampelas berdiam di Kabupaten Donggala.
Di samping 12 kelompok etnis, ada juga beberapa suku terasing yang hidup di daerah pegunungan, seperti suku Da'a di Donggala, suku Wana di Morowali, suku Seasea di Banggai dan suku Daya di Buol Tolitoli. Meskipun masyarakat Sulawesi Tengah memiliki sekitar 22 bahasa yang berbeda antara suku yang satu dengan yang lain, namun masyarakat dapat berkomunikasi satu sama lain menggunakan bahasa Indonesia sebagai bahasa nasional dan bahasa pengantar sehari-hari (dalam http: //nadhy-math. blogspot. com/2012/01, diakses pada 17/7/2017).

Selain penduduk asli, Sulawesi Tengah dihuni pula oleh migran dari Bali, Jawa, Nusa Tenggara Barat, Nusa Tenggara Timur, Bugis, Makasar, serta etnis lainnya di Indonesia sejak awal abad 19 dan mereka sudah membaur. Berdasarkan data tersebut, prosentase sebaran penganut agama di Provinsi Sulawesi Tengah pada 2014 terdiri atas (1) Islam berjumlah 2.006.754 orang (73\%), (2) Kristen berjumlah 490.379 orang (17,9 \%), (3) Katholik berjumlah 33.254 orang (1,21 \%), (4) Hindu berjumlah 133.632 orang (4,9 \%), dan Buddha berjumlah 16.125 orang $(0,6 \%)$ dari total penduduk Sulawesi Tengah pada tahun 2014 yang berjumlah 2.740 .168 orang.

\section{Identifikasi Sebaran Seni dan Budaya Bernuansa Keagamaan}

Seni dan Budaya Keagamaan Bernuansa

Animisme/ Dinamisme

\section{Patung Tadulako}

Patung Tadulako terdapat di Lembah Besoa, Kecamatan Lore Tengah, Kabupaten Poso. Patung ini pertama kali dilaporkan oleh orang Belanda bernama Kilian yang menyebutnya Watumeangka. Raven pada 1918 menyebutnya Tadulako, dan Kruyt juga menyebutnya Tadulako. Penamaan tersebut berdasarkan penamaan yang diberikan penduduk yang bermukim di sekitarnya. Patung ini tidak berkaki, tertanam dalam tanah, memakai simbol Tadulako yang berarti panglima perang pada bagian dada, mata bulat melotot dan bagian pelipis terdapat benjolan yang menunjukkan telinga. Oleh penduduk setempat patung serupa ini digambarkan sebagai personifikasi panglima perang dan juga nenek moyang mereka. Pada saat tertentu penduduk setempat memberikan sesajian sebagai sesajian untuk mencari berkah (Dinas Kebudayaan dan Pariwisata Provinsi Sulawesi Tengah, 2013: 8).

\section{Patung Langke Bulava}

Patung Langke Bulava terdapat di Lembah Bada, Kecamatan Lore Selatan Kabupaten Poso. Berbentuk Silinder dan pertama kali dilaporkan 
Sarasin pada 1908 dan A.C. Kruyt pada 1909. Patung ini tertanam dalam tanah, kepala besar di banding badannya, tidak bermulut, dagu berbentuk lonjong, mata bulat, ujung hidung rata serta pangkal hidung atau mata bersambung dengan mata. Di atas dahi hidung terdapat motif lengkungan yang menyerupai ikat kepala atau mahkota yang dihiasi oleh empat buah bulatan berderet. Demikian pula tangan dan jarinya, terletak di bagian depan dan di antara kedua tangan itu terletak alat kelamin wanita. Penduduk sekitar menyebutnya patung Langke Bulava (Langke $=$ gelang dan Bulava $=$ emas) yang melambangkan Dewi Kecantikan yang banyak dikunjungi oleh anak-anak gadis untuk meminta berkah kecantikan (Dinas Kebudayaan dan Pariwisata Provinsi Sulawesi Tengah, 2013: 9).

\section{Kalamba}

Patung Kalamba terdapat di Lembah Besoa, Kecamatan Lore Tengah Kabupaten Poso. Penutup patung tersebut dari batu yang terletak di atas tanah tak jauh dari Kalamba itu. Tebal dindingya $20 \mathrm{~cm}$, sedangkan diameter lubangnya $84 \mathrm{~cm}$ dan dalamnya $120 \mathrm{~cm}$. Badan kalamba dihiasi dengan lima buah pola hias garis melingkar yang jarak satu sama lain makin ke bawah makin besar. Kalamba ini dilengkapi dengan penutup dan memiliki pegangan di bagian tengah yang berupa tonjolan. Tutupnya di bagi lima bagian yang sama oleh lima buah hiasan motif hewan dalam posisi jongkok. Penduduk menganggap hiasan ini menyerupai kera. Menurut informasi dari penduduk, Kalamba ini diduga sebagai tempat mandi raja. Namun menurut Tim survei Pusat Penelitian Pengembangan Arkeologi Nasional tahun 2005bahwa Kalamba ini digunakan sebagai tempat penguburan. Pada eskavasi yang dilakukan oleh Bidang Prasejarah Puslitbang Arkenas tahun 2000 di Lembah Besoa dapat diketahui bahwa salah satu fungsi Karamba adalah sebagai wadah penguburan kedua secara komunal (Dinas Kebudayaan dan Pariwisata Provinsi Sulawesi Tengah, 2013: 10).

\section{Patung Palindo}

Patung Palindo terdapat di situs Padang Sepe, Lembah Bada, Kabupaten Poso. Masyarakat yang bermukim di sekitar situs menyebutnya patung Palindo (penghibur), atau perwujudan dari nenek moyang mereka sebagai pahlawan yang bernama Tosalogi. Dikisahkan, Tosalogi memimpin rakyat Bada berperang melawan orang dari Masamba. Patung ini ditemukan dalam keadaan miring 30 derajat dan berukuran tinggi $400 \mathrm{~cm}$. Pada patung dipahatkan muka manusia memakai ikat kepala (pekabalu), mata bulat melotot, tangan mengarah ke phallus yang menonjol, serta tanpa kaki (Dinas Kebudayaan dan Pariwisata Provinsi Sulawesi Tengah, 2013: 9-10).

\section{Seni dan Budaya Keagamaan Bernuansa Islam Musik Kakula}

Musik Kakula merupakan seni musik tradisional suku Kaili khususnya dan masyarakat Sulawesi Tengah pada umumnya sudah sangat sukar menentukan kapan mulai dikenal oleh masyarakat di daerah ini. Pada tahun 1618 agama Islam masuk di daerah ini dengan membawa serta pula kebudayaannya. Mengikuti penyebarpenyebar Islam ini sebagai alat pendukung dakwah, mereka membawa serta alat musik yang terbuat dari tembaga/kuningan yang sekarang dikenal dengan Musik Kakula. Musik Kakula yang kita kenal sebagai salah satu seni musik tradisional suku Kaili khususnya dan masyarakat Sulawesi Tengah pada umumnya sudah sangat sukar menentukan kapan mulai dikenal oleh masyarakat di daerah ini. Pada tahun 1618 agama Islam masuk di daerah ini dengan membawa serta pula kebudayaannya. Mengikuti penyebar-penyebar Islam ini sebagai alat pendukung dakwah, mereka membawa serta alat musik yang terbuat dari tembaga/kuningan yang sekarang ini kita kenal dengan Musik Kakula. Alat musik tersebut berbentuk bulat dan pada bagian tengalmya muncul atau munjung, sama dengan bonang di Pulau Jawa.

\section{Upacara Nopamada}

Upacara Nopamada mengajarkan/mengingatkan atau menuntun orang yang sekarat dengan suatu petunjuk atau isyarat tertentu, yang dipercayai sebagai suatu cara yang membuka jalan lempang, agar roh dapat ke luar dengan tenang dari dalam tubuh pada saat menghembuskan napas terakhir. Ajaran tersebut biasa disebut "jalan nggamatea" (jalan menuju kematian), yang isinya mempelajari tandatanda akan datangnya ajal dan jalan yang ditempuh oleh roh seseorang, pada saat menghembuskan napas terakhir menuju alam baka. Ajaran ini diperoleh melalui tarikat dengan guru-guru agama, yang biasanya diajarkan kepada seseorang dalam kelambu, dengan sangat rahasia. Pengetahuan tersebut tidak diajarkan kepada sembarang orang melainkan hanya kepada orang-orang tertentu saja, karena mereka yang dianggap ahli dan bertugas mengajar orang-orang yang sedang dalam keadaan sakarat tersebut. Dalam keadaan seseorang rilara 
nuadanga diadakan pengajian AI-Qur'an (surat Yasin) dari salah seorang anggota yang hadir, yang dianggap memiliki suara yang fasih dan lagu yang baik. Yang bertugas mengajarkan/membisikkan ajaran kepada orang yang sakarat tersebut adalah keluarga yang terdekat, yang dianggap guru atau pegawai syara yang diundang untuk itu. Kalimat yang dibisikkan ke telinga (nipotuntuaka ritalinga) adalah kalimat Tauhid yaitu Laa Ilaha illallah. Siapa yang mampu mengucapkan kalimat tauhid tersebut, dipercayai bahwa orang yang meninggal tersebut pasti masuk Surga (dalam http: //telukpalu. $\mathrm{com} / 2007 / 02 /$ kesenian-tradisional-sulawesitengah, diakses pada 10/7/2017).

\section{Musik Gambusu}

Alat kesenian Gambusu tersebar ke desa-desa di Tanah Kaili, terutama pada masa agama Islam masuk ke daerah ini. Bahkan sampai sekarang orang-orang masih tetap mencintainya, sehingga permainan gambus yang mengikuti tari jepeng berkembang dimana-mana. Mungkin karena pemegang gambus ini adalah orang-orang Arab alam syair-syair lagunya, maka sampai sekarang penduduk pribumi ikut pula membawakan syairsyair yang berbahasa Arab. Akan tetapi karena perkembangannya sekarang ini telah digunakan bahasa Indonesia, yang komunikatif, membawakan pesan, petuah, dan nasehat yang berhubungan dengan agama Islam (dalam http: //telukpalu. com $/ 2007 / 02 /$ kesenian-tradisional-sulawesitengah, diakses pada 10/7/2017).

\section{Rebana}

Alat ini berfungsi sebagai hiburan musik pada waktu Maulid Nabi Muhammad SAW dan pada waktu mengantar pengantin lelaki bersamasama dengan sanak saudara dan handai tolan, yang diiringi dengan syair-syair yang indah. Bilamana bunyi rabana terdengar, orang menafsirkan bahwa ditempat itu ada pengantin atau ada peringatan Maulid. Kalau pada pesta pengantin, dari jauh sudah kedengaran musiknya, orangorang dirumah pengantin perempuan bersiap pula untuk menyambut kedatangan pengantin dengan membunyikan alat kesenian yang namanay kakula. Dan disaat-saat itulah pengantin perempuan menanti dengan hati berdebar-debar. Ada syair yang dipakai orang di Tanah Kaili tentang rabana ini yakni: "du du nurabana, radu-radu nubambara" terjemahnya Bunyi (du....du) rabana, dadaberdebardebar. Jadi ada hubungan antara bunyi rebana dan sang gadis si calon instri. Kalau didengar syair-syair yang dibawakan oleh para pemain kebanyakan dan bahkan hampir seluruhnya memakai Bahasa Arab, pada waktu Maulid misalnya di Sulawesi Tengah khususnya di Tanah Kaili agama Islam masuk pada abad ke 17, sehingga orang mengatakan bahwa seni rabana adalah seni untuk orang Islam (dalam http: //telukpalu.com/2007/02/kesenian-tradisionalsulawesi-tengah, diakses pada 10/7/2017).

\section{Suaka Nuwiata;}

Wiata dalam bahasa Lindu berarti roh makhluk yang sudah meninggal atau makhluk "halus". Di kalangan orang Lindu yang masih memegang teguh tradisinya terdapat kepercayaan kuat yang meyakini bahwa roh orang yang sudah meninggal dunia sebenarnya mendiami daerahdaerah tertentu. Roh itu pada waktu-waktu khusus datang ke tempat sanak keluarganya yang masih hidup. Misalnya pada saat upacara adat panen. Dalam tradisi orang Lindu, Suaka $\mathrm{Nu}$ Wiata adalah wilayah konservasi yang mutlak. Di tempat ini, seseorang tidak dibolehkan masuk apalagi sampai melakukan kegiatan menebang kayu atau kegiatan yang sifatnya merusak hutan. Pelanggaran terhadap ketentuan ini akan memperoleh sanksi adat yang Suaka Nu Wiata tidak hanya terletak di tempat yang jauh dari pemukiman penduduk, tetapi juga terdapat di tempat yang dekat dengan perkampungan. Sehingga di tepi jalan antara desa Langko, Tomado dan Anca terdapat hutan yang cukup lebat. Hutan-hutan ini terletak jauh dari tapal batas Taman Nasional yang ditetapkan pemerintah (dalam http://nadhy-math.blogspot.com/2012, diakses pada 10/6/2017).

\section{Mantra Percintaan}

Di kalangan masyarakat Tojo terdapat mantra untuk percintaan yang berbunyi: "Koko ri mundiku/ Ula Tepu ri rayaku/ Ende ko maucaya ri rupaku/ Murilaya Kimindara duaga ri mata matana/ Lillahi ta'ala." (Ya...Tuhanku ber pertlolongan kepadaku/ Atas penghinaan dari gadis yang mengecewakan diriku). Selain itu, di masyarakat lembah Lore (Napu) juga terdapat mantra percintaan yang berbunyi: "Kupati Malone-lone/Kupati mabungabunga/Arahmata Ntara dia/Kupidi Sule kupidi matana/Nuraka Nurasa/Sulemu Suleku/Hu'u Kumpayakun" (Ku buat dirinya/Seperti orang yang berbunga-bunga/Kuarahkan pada dirinya/ Kubuat perasaan pada matanya/Merasakan cinta terhadapku/Sehingga perasaanku adalah perasaanmu/Jadi, maka jadilah)" (Hasan, 2005: 218-219). 


\section{Mantra untuk menundukkan orang sombong}

"Barangkau barangkau/Tudu tumai pol barangkau baranhgkau/Ri yallah bismillah" (Oh Tuhan/Tundukkanlah perasaan/orang-orang yang memusuhiku)" (Hasan, 2005: 219).

\section{Mantra untuk bertani}

Di Masyarakat Tojo terdapat mantra agar berhasil dalam bertani, yaitu "Assalamu 'alaikum Assalmu 'alaina"/Tudang Muhammad polisina Tanae/Parampulu tendrealle parama seta" (Hasan, 2005: 227).

\section{Tradisi untuk selamatkan jabang bayi}

Di daerah Togean terdapat tradisi jika perempuan hamil keluar rumah kepalanya ditutup dengan kain sarung atau handuk. Sebab, menurut keyakinan mereka, pongko atau Pontianak dapat mengetahui wanita hamil atau tidak itu dari kepala. Di usia menjelang tiga bulan, sang ibu sang ibu senantiasa menutup atau membungkus perutnya dengan pukat/ jala dan diisi di dalamnya dengan kulit penyu, gigi cumi, biji srikaya, Qur'an kecil, tepat di tengah perut. Pantangan bagi ibu hamil ini yaitu: (1) tidak boleh berkelahi apalagi dengan suami atau orang tua, (2) jangan kikir, (3) jangan sembarangan membicarakan orang lain apalagi kejelekannya, (4) jika ada yang meminta yang berhubungan dengan dapur seperti garam, bawamg, rica atau minya kelapa agar memberinya walau sedikit. Untuk menghindari makhluk halus bisa juga dengan disisipkan lemon di sebelah jendela kamar dekat sang ibu yang hamil atau membawanya jika ingin keluar rumah (Hasan, 2005: 237-238).

\section{Upacara tolak bala sebelum melaut}

Sebelum turun melaut, para nelayan di Poso pesisir, Tojo, Ampana, Kepulauan Togean, Bungku, Mori, mengadakan Upacara Tolak Bala. Agar ikan besar tidak mengganggu dibuang srikaya, mencelupkan botol kemudian parang dipukulkan atau tangan dicelup kemudian mata tangan dipijitpijit sambil digoyang-goyangkan. Agar nelayan terhindar dari badai/ angina ribut, sang nelayan telanjang bulat dan diam sejenak. Ada juga dengan ucapan seperti: "Nabi Tuti" (Nabi perempuan) "Nabi haeder" (Nabi laki-laki) (Hasan, 2005: 237238).

\section{Nogero Jene (Membatalkan Air Wudu)}

Nogene Jene merupakan salah satu rangkaian dari proses pernikahan yang dilakukan setelah pengucapan ijab qabul. Rangkaian ini dimaksudkan sebagai acara penyentuhan pertama oleh seorang suami kepada istrinya dengan menyentuh salah satu bagian muka dari bahu sampai hidung. Sebelum proses penyentuhan pertama ini, sang putri berada di dalam kamar atau kelambu bersama dengan ibu pengantin. Pada saat suami tiba di depan pintu kamar atau kelambu, orang tua mengantarnya mengetuk pintu sambil mengucapkan "Assalamu 'alaikum 'Ibadu Rahim" tiga kali. Ketika ibu pengantin sudah menjawabnya "Wa'alaikum salam Ibadu Rahman", pengantin lakilaki sudah memasuki kamar atau kelambu. Dalam acara ini yang biasa dijadikan ajang permainan, pihak perempuan memperlakukan syarat yang diperlukan. Hal ini seperti pengantin laki-laki harus memasukkan uang atau gula-gula sebanyak mungkin agar pintu dapat dibuka. Selanjutnya pihak laki-laki dipersilakan masuk oleh ibu pengantin. Sang suami bersama pengantarnya memasuki kamar untuk melakukan sentuhan pertama (Hajar, 2008: 77-78).

\section{Tari Jeppeng}

Jeppeng berasal dari istilah Zafin. Perubahan ini disebabkan orang Kaili susah mengucapkan konsonan " $Z$ " sehingga mengucapkannya "J". Kesenian ini pada mulanya berasal dari tanah Aran yang dibawa oleh orang Yaman ke Gujarat. Pada awal abad ke-16, kesenian ini juga dibawa oleh saudagar Arab dari Hadramaut ke Johor dan berkembanga di kerajaan Riau. Tarian ini pun berkembang di berbagai daerah lainnya. Adapun perkembangannya di Palu sudah ada sejak Guru Tua (Sayyid Idrus bin Salim al-Jufri) berada di kota Palu pada tahun 1930. Di dalam tarian ini terdapat nuansa Islami seperti syair-syair yang berisi pujian kepada Allah swt, Nabi Muhammad saw, kewajiban dan larangan dalam agama Islam yang bertujuan mendidik masyarakat agar selalu mengingat dan mengamalkan ajaran Islam (Musni, 2014: 66).

\section{Seni dan Budaya Keagamaan Bernuansa Kristiani Padungku (Paska Panen)}

Upacara ini pada mulanya ditujukan bagi Alo (dewa-dewa) dan leluhur atau nenek moyang penduduksetempatyang dipercayai telah membantu masyarakat dengan memberika kesuburan tanah dan panen padi yang melimpah. Namun, dalam perkembangannya, upacara paska panen tersebut menjadi sangat erat hubungannya dengan kegiatan religious yang dilakukan oleh agama Kristen. Gereja mengadopsi Padungku sebagai ungkapan rasa syukur kepada Tuhan. Sebelum melakukan proses ibadah, semua keluarga akan membawa sebagian 
hasil panen mereka ke gereja yang disebut "buah sulung" (buah pertama). Dalam prosesnya, hasil panen tersebut didoakan oleh pendeta (Tosadu, 2013: 63-76).

\section{Upacara Perkawinan Adat Pamona}

Upacara ini dimulai dengan adat peminangan bungkus pinang. Sebab, menurut adat Pamona Poso, bila ada tamu yang datang harus disuguhi buah pinang sebagai tanda kehormatan. Pihak rombongan pria selanjutnya melakukan tahapantahapan berikut: (1)mebolai (mendatangi rumah) pengantin wanita, (2)pekawisia (pengangkatan menjadi warga) Pamona, (3)peompo (hadangan ketika rombongan pengantin pria akan memasuki areal pesta perkawinan adat), (4)Pemamongoka (penyuguhan sirih Pinang, (5)Pabusalaka Olim Porongo (penyerahan mas kawin), (6)sampapitu (penyatuan tujuh macam benda yaitu baki, sehelai kain, selimut, sepotong kain untuk ikat kepala, kotak sirih, dua buah piring, dan pengurai mulut. Selanjutnya kedua mempelai dibawa ke gereja untuk nikah kudus dan diakhiri dengan resepsi (Moula, 2014: 47-52).

\section{Adat Pesta Rambu Solo}

Acara ini merupakan pesta kematian oleh etnis Toraja di kota Palu. Mayat yang akan dipestakan pemakamannya dilakukan dengan pemotongan hewan demi bekalnya di dunia dan akhirat (puya). Sebab, mereka beranggapan semua harta yang dikorbankan sewaktu pesta pemakamannya akan menjadi milik kekayaannya di dunia dan akhirat. Karena itu, dalam upacara Rambu Solo ini persembahan ditujukan kepada roh orang yang meninggal dunia dengan pengorbanan kerbau dan babi. Mereka percaya jika orang yang meninggal tidak dipestakan dengan pemotongan hewanhewan tersebut maka rohnya akan gentayangan hingga tidak bisa masuk ke dunia arwah (Bunga, 2005: 53-55).

\section{Seni dan Budaya Keagamaan Bernuansa Hindu Upacara Potong Gigi}

Di Tambarana sebagai ibu kecamatan Poso Pesisir Utara, Kabupaten Poso, jumlah penduduk desa ini berdasarkan agama yang dianut, terdiri dari Islam (2.123), Protestan (1113), Hindu (1027), dan Khatolik (11). Di kalangan umat Hindu terdapat upacara yang bermula dari mitologi Bhatara Kala mencari ayah dan ibunya. Bhatara Siwa memberitahu Bhatara Kala agar memotong taring yang tajam itu terlebih dahulu. Sebab jika taringnya yang tajam itu sudah dipotong maka secara otomatis dia akan bertemu siapa yang menciptakannya. Hal ini dilakukan dengan menaikkan anak-anak yang akan dipotong giginya naik ke bale tempat pelaksanaan potong gigi atau mepandes dengan terlebih dahulu menginjak banten (sesajen) yang telah disediakan sebagai simbol mohon kekuatan kepada Sang Hyang Widi Wasa (Murniasih, 2012: 38-54).

\section{Krama Adat Kerta Winangun;}

Istilah ini merupakan organisasi suka duka yang dibuat oleh masyarakat Hindu di Palu. Organisasi tersebut mengambil aspirasi dari sistem Desa Adat atau yang saat ini disebut Desa Pakraman di Bali. Keberadaan organisasi ini diawali oleh aktivitas seperti arisan pada keluarga-keluarga Hindu asal Bali di wilayah kota Palu. Dalam setiap Desa Adat umat Hindu di Palu mempunyai Awigawig yaitu peraturan yang berpedoman kepada (1) Sastra desa (ketentuan-ketentuan yang bersumber dari ajaran Hindu, (2) Purwa Dresta (ketentuanketentuan yang bersumber dari tradisi atau kebiasaan yang masih berlaku, (3) Loka Dresta (ketentuan-ketentuan bersumber dari pandangan Krama Adat, dan (4) Desa Dresta yaitu ketentuanketentuan yang bersumber dari pandanganpandangan khusus di lingkungan Banjar Adat yang bersangkutan (Karsini, 2012: 47).

\section{PENUTUP}

Penelitian ini menghasilkan identifikasi terhadap 21 nama seni budaya bernuansa keagamaan di Kota Palu dan Kabupaten Poso Provinsi Sulawesi Tengah. Adapun sebaran berdasarkan nuansa agama pada nama-nama seni dan budaya keagamaan sebagai berikut: 4 buah bernuansa animisme/dinamisme (19\%), yaitu patung Tadulako, patung Langke Bulava, Kalamba, dan patung Palindo; 12 buah (57\%) bernuansa Islam, yaitu musik kakula, upacara Nopamada, musik gambusu, rabana, suaka nuwiata, mantra untuk percintaan, mantra untuk menundukan orang sombong, mantra untuk bertani, tradisi selamatkan jabang bayi, upacara tolak bala sebelum melaut, Nogero Jene (membatalkan air wudu), dan tari Jeppeng. Sedangkan yang bernuansa Kristen 3 buah (14\%), yaitu: Padungku (Upacara Paska Panen), upacara perkawinan adat Pamona, dan adat pesta Rambu Solo. Yang bernuansa Hindu sebanyak 2 buah (9,5\%), yaitu upacara Potong Gigi dan Krama Adat Kerta Winangun.

Dengan demikian, sebaran tersebut dapat menjadi data untuk melihat identifikasi seni dan 
budaya keagamaan di Sulawesi Tengah berdasarkan penganut agama dan sebaran tiap-tiap agama, yang secara keseluruhan terdiri mencakup, Islam berjumlah 2.006.754 orang (73\%), Kristen berjumlah 490.379 orang (17,9\%), Katholik berjumlah 33.254 orang $(1,21 \%)$, Hindu berjumlah 133.632 orang (4,9 \%), dan Buddha berjumlah 16.125 orang $(0,6$ \%) dari total penduduk Sulawesi Tengah pada 2014 yang berjumlah 2.740 .168 orang.

Identifikasi seni dan budaya keagamaan ini dapat dikatakan sebagai pandangan ahli sosiologi dan antropologi yang menyatakan agama sebagai fenomena sosial dan kultural. Dengan demikian, agama menjadi satu elemen penting yang memberi corak dari sebuah masyarakat dan sebuah kebudayaan. Hal ini menegakkan pula isi Renstra Direktur Jenderal Kebudayaan 2010-2014 di halaman enam, yang menyatakan, persebaran kebudayaan (difusi) maupun akulturasi (hibridasi unsur budaya), kemunculan agama-agama besar di dunia banyak mempengaruhi perkembangan kebudayaan di Indonesia, mulai dari agama yang bersifat politheisme hingga monotheisme. Kemampuan sistem budaya di Indonesia dalam mengadopsi unsur budaya agama dan tentu saja beradapatasi dengan unsur-unsur baru merupakan cerminan sifat sistem kebudayaan di Indonesia yang bersifat akulturatif.

\section{UCAPAN TERIMA KASIH}

Penulis menghaturkan terima kasih kepada Kepala Pusat Lektur Khazanah dan Manajemen Organisasi yang telah mendanai penelitian ini dan memberikan kesempatan untuk meneliti seni dan budaya di Provinsi Sulawesi Tengah. Penulis juga mengucapkan terima kasih kepada redaksi Jurnal Al-Qalam yang berkenan menerbitkan tulisan ini. Tak lupa pula, penulis mengucapkan terima kasih kepada semua informan di lapangan, yang banyak membantu selama melakukan penelitian ini.

\section{DAFTAR PUSTAKA}

Abubakar, Jamrin. 2012. Misteri Negeri Seribu Megalit. Yogyakarta. Ladang Pustaka.

Bunga, Simon Paa. 2005. Peranan Adat terhadap Mobilitas Sosial Etnis Toraja di Kota Palu Sulawesi Tengah.
Skripsi. Program Studi Antropologi. FISIP. Universitas Tadulako. Palu.

Hajar, Andi. 2008. Upacara Perkawinan Etnis Kaili di Kota Palu. Skripsi. Program Studi Antropologi FISIP. Universitas Tadulako. Palu.

Hasan, Syamsuddin R. Koida, Arif. 2005. Budaya \& Adat Istiadat Poso. Yogyakarta. Pustaka Timur.

Karsini, Kadek. 2012. Sejarah Krama Adat Kertha Winangun Kota Palu. Skripsi. Program Studi Pendidikan Sejarah. Jurusan Pendidikan IPS. FKIP. Universitas Tadulako. Palu.

Moula, Ika Suryaningsi. 2014. Upacara Perkawinan Adat Suku Pamona di Desa Wayura Kecamatan Pamona Tenggara Kabupaten Poso. Skripsi. Program Studi Antropologi FISIP Universitas Tadulako. Palu.

Murniasih, Ni Wayan. 2012. Upacara Potong Gigi Orang Hindu di Desa Tambarana. Skripsi. Program Studi Pendidikan Sejarah Jurusan Pendidikan IPS. FKIP. Universitas Tadulako. Palu.

Musni, Sarifah. 2014. Studi Hitoriografi Tari Jeppeng di Kota Palu. Skripsi. Program Studi Antropologi. FISIP. Universitas Tadulako. Palu.

Pedoman Berkunjung Museum Sulawesi Tengah. 2013. UPT Museum Sulawesi Tengah, Dinas Kebudayaan dan Pariwisata, Pemerintah Provinsi Sulawesi Tengah, Palu.

Renstra Direktorat Jenderal Kebudayaan 2010-2014

Sutrisno, dkk., 2005. Sejarah Daerah Sulawesi Tengah. Dinas Kebudayaan dan Pariwisata Pemerintah Daerah Provinsi Sulawesi Tengah.

Tosadu, Frans Ferdianus, 2013. Ritual "Padungku" pada Etnis Pamona di Desa Tindoli Kecamatan Pamona Tenggara Kabupaten Poso. Skripsi. Program Studi Antropologi. FISIP. Universitas Tadulako. Palu.

\section{Sumber Internet:}

Makalah Sosial-Budaya Sulawesi Tengah, dalam http: // nadhy-math.blogspot.com/2012/01, diakses pada 17 Juli 2017.

http://mutia-dwi.blogspot.com/2012/03/budayasulawesi-tengah-dan-seni.html, diakses pada 3 Juni 2017.

http://telukpalu.com/2007/02/kesenian-tradisionalsulawesi-tengah, diakses pada 10 Juli 2017).

http://www.dw.com/id/interview-sejarah-seni-purbaperlu-ditulis-ulang/dan http: //www. dw. com/id/ lukisan-gua-sulawesi-menulis-kembali-sejarah/, diakses pada 24 Mei 2017.

http://telukpalu.com/2007/02/kesenian-tradisionalsulawesi-tengah, diakses pada 10 Juli 2017) 